\title{
Autophagy and Digestive Disorders: Advances in Understanding and Therapeutic Approaches
}

\author{
Wynn Thein ${ }^{\dagger}$, Wah Wah $\mathrm{Po}^{\dagger}$, Won Seok Choi and Uy Dong Sohn* \\ College of Pharmacy, Chung-Ang University, Seoul 06974, Republic of Korea
}

\begin{abstract}
The gastrointestinal $(\mathrm{Gl})$ tract is a series of hollow organs that is responsible for the digestion and absorption of ingested foods and the excretion of waste. Any changes in the GI tract can lead to GI disorders. GI disorders are highly prevalent in the population and account for substantial morbidity, mortality, and healthcare utilization. GI disorders can be functional, or organic with structural changes. Functional GI disorders include functional dyspepsia and irritable bowel syndrome. Organic GI disorders include inflammation of the GI tract due to chronic infection, drugs, trauma, and other causes. Recent studies have highlighted a new explanatory mechanism for GI disorders. It has been suggested that autophagy, an intracellular homeostatic mechanism, also plays an important role in the pathogenesis of GI disorders. Autophagy has three primary forms: macroautophagy, microautophagy, and chaperone-mediated autophagy. It may affect intestinal homeostasis, host defense against intestinal pathogens, regulation of the gut microbiota, and innate and adaptive immunity. Drugs targeting autophagy could, therefore, have therapeutic potential for treating GI disorders. In this review, we provide an overview of current understanding regarding the evidence for autophagy in GI diseases and updates on potential treatments, including drugs and complementary and alternative medicines.
\end{abstract}

Key Words: Functional dyspepsia, Irritable bowel syndrome, Inflammation, Autophagy

\section{INTRODUCTION}

Autophagy, which literally means self-eating, is an intracellular homeostatic mechanism. During stressful conditions, damaged cytoplasmic components and foreign antigens are degraded inside the autolysosome with the help of lysosomal hydrolases and lipases (Klionsky, 2007; Maes et al., 2013). Generally, autophagy can be classified into three primary forms: macroautophagy, microautophagy, and chaperonemediated autophagy. These three forms show different morphologies (Klionsky, 2005). An autophagosome is formed by the sealing of a double-membrane compartment known as a phagophore. The autophagosome then fuses with a lysosome to form an autolysosome. This process is extensively modulated by various autophagy-related genes (ATG) and proteins (Wang and Klionsky, 2003). During stressful conditions, autophagy removes polyubiquitinated protein aggregates, degrades invading pathogens through a process called xenophagy, regulates the release of pathogen-induced pro-inflammatory cytokines, and participates in the development of lymphocytes and in antigen presentation (Boya et al., 2013).
Autophagy contributes substantially to intestinal homeostasis, host defense against intestinal pathogens, regulation of the gut microbiota, and innate and adaptive immunity (Mizushima, 2018). Changes in autophagy have been implicated in the pathogenesis of various diseases, including gastrointestinal $(\mathrm{Gl})$ diseases such as gastritis, inflammatory bowel disease (IBD), GI motility dysfunction, and GI cancers (Xavier and Podolsky, 2007; Castaño-Rodríguez et al., 2015). In this review, we provide an updated and comprehensive overview of the current understanding of autophagy in GI diseases, including the underlying mechanisms of autophagy in the pathophysiology of $\mathrm{GI}$ diseases, as well as several recent autophagy-related pharmacological interventions in the treatment of $\mathrm{Gl}$ diseases.

\section{AUTOPHAGY AND CHRONIC ATROPHIC GASTRITIS}

Chronic atrophic gastritis (CAG) is a disorder characterized by the reduction or loss of the mucosal glands found in the fundus and the body of the stomach. These glands may be

\section{Open Access https://doi.org/10.4062/biomolther.2021.086}

This is an Open Access article distributed under the terms of the Creative Commons Attribution Non-Commercial License (http://creativecommons.org/licenses/by-nc/4.0/) which permits unrestricted non-commercial use, distribution, and reproduction in any medium, provided the original work is properly cited.
Received May 1, 2021 Revised May 11, 2021 Accepted May 24, 2021

Published Online Jun 15, 2021

\section{*Corresponding Author}

E-mail: udsohn@cau.ac.kr

Tel: +82-2-820-5614, Fax: +82-2-826-8752

${ }^{\dagger}$ The first two authors contributed equally to this work. 
lost on account of fibrosis, or more frequently pseudo-pyloric or intestinal metaplasia, due to chronic inflammation (Correa, 1988; Rugge et al., 2002). The histological changes may be associated with Helicobacter pylori infection, or may be due to immune-mediated attacks on the gastric parietal cells. Autophagy plays a crucial role in the development of CAG (Wang et al., 2020b).

\section{CAG FOLLOWING H. PYLORI INFECTION}

\section{Pathophysiology}

$H$. pylori, a microaerophilic gram-negative bacterium, has been widely accepted as the major risk factor for the development of gastric cancer since the International Agency for Research and Cancer (IARC) of the World Health Organization designated it as a type 1 carcinogen in 1993 (International Agency for Research on Cancer, 1994). H. pylori-induced CAG is the first step in the multistep cascade of gastric cancer. The early phase of $H$. pylori infection elicits an acute inflammatory response with temporary clinical symptoms such as nausea and vomiting, which develops into chronic gastritis (Marshall and Warren, 1984). The two most important virulence factors secreted are vacuolating cytotoxin (VacA) and effector protein cytotoxin-associated gene A (CagA) (Xiang et al., 1995). In chronic infection, $H$. pylori adheres to the epithelial surface and degrades it, causing mucin loss, cytoplasmic basophilia, increased mitosis, and hyperchromatic nuclei (Carneiro et al., 1992; Leung et al., 1992). Generally, infiltration of the gastric mucosa with neutrophil granulocytes plays an important role in the immune response against $H$. pylori, triggered by high levels of interleukin-8 (IL-8). IL-8 attracts neutrophils, releasing oxyradicals to block oxidative stress (Hardbower et al., 2014).

Lymphocyte infiltration is also seen during the formation of lymphoid follicles, which is initiated by Th (T-helper cell)-1 and Th-17-responses involving the release of proinflammatory cytokines such as nuclear factor kappa-light-chain-enhancer of activated $\mathrm{B}$ cells (NF-kB), interferon gamma (IFN- $\gamma$ ), and IL-17 (Khamri et al., 2010). H. pylori has been shown to regulate the autophagy pathway of the host by degrading the cytosolic proteins, organelles, and pathogens within the cell. The channel-forming activity of VacA is necessary and sufficient to induce autophagy in gastric epithelial cells (Terebiznik et al., 2009; Wang et al., 2009). VacA-mediated autophagy disrupts autophagosome maturation following prolonged exposure to the toxin (Raju et al., 2012). In chronic H. pylori infection, microRNA (miR)-30b is upregulated and compromised autophagy maintains the $H$. pylori infection (Xiao et al., 2009; Tang et al., 2012). A total of 28 autophagic genes, including ATG16L1, ATG5, ATG4D, and ATG9A, are downregulated in chronic $H$. pylori infection (Castaño-Rodríguez et al., 2015; Tanaka et al., 2017). Cag $A^{+} H$. pylori strains located in the gastric mucosa upregulate inflammatory cytokines, whereas autophagic proteins are downregulated by the c-Met/AKT (MET family receptor tyrosine kinase/protein kinase) signaling pathway, thereby inhibiting autophagy in chronic $H$. pylori infection (Li et al., 2017).

\section{Therapeutic approaches}

According to clinical guidelines and consensus statements (Sugano et al., 2015; Chey et al., 2017; Malfertheiner et al., 2017), all patients with CAG who have $H$. pylori infection should receive eradication therapy when there are no other considerations. The goals of treatment in such individuals include cure of infection, resolution of mucosal inflammation, recovery of gastric acid secretion, prevention of lesions in the gastric mucosa, and prevention of gastric cancer (Lee et al., 2016).

The first-line therapy for $H$. pylori eradication is antibiotics, which is limited in effectiveness due to antibiotic resistance. A non-antibiotic therapy is, therefore, required. Catechins, natural phenols found in tea, red wine, fruit, and some plants, have antioxidant and anti-microbial effects (Mabe et al., 1999). Sialic acid, mostly found in GI mucins and milk, has an anti-adhesive effect against $H$. pylori infection (Simon et al., 1997). The catechin and sialic acid combination therapy can eradicate $H$. pylori and ameliorate $H$. pylori-induced epithelial cell death by enhancing autophagy and decreasing the activation of caspase-1 and the secretion of IL-1 (Yang et al., 2013). Thus, this combination therapy could provide an alternative regimen for treating $H$. pylori-induced atrophic gastritis. Moreover, resveratrol, a potent anti-inflammatory and antioxidant polyphenol mostly found in berries, nuts, and grape skin, decreases the levels of IL- 8 and inducible nitric oxide synthase and inhibits NF- $\mathrm{BB}$ activation in $\mathrm{H}$. pylori-induced gastritis (Zhang et al., 2015). Resveratrol also exerts inhibitory effects on translation, outer membrane protein transport, ATP synthase, and other possible oxidative damage against $H$. pylori (Xia et al., 2020). Therefore, resveratrol has potential as a treatment option for $H$. pylori-induced gastritis.

Eudesmin, extracted from Fatsia polycarpa Hayata, efficiently eradicates $H$. pylori and enables recovery from the $H$. pylori-induced gastric epithelial cell death mediated by autophagy and apoptosis. This eradication is achieved by decreasing the expression of proteins involved in apoptosis and autophagy, such as LC-3B, caspase-3, caspase-9, caspase-8, Bax, and Bid (Yang et al., 2018). Eudesmin treatment provides a unique and promising non-antibiotic therapy for $H$. pylori infection. Furthermore, astaxanthin, a carotenoid pigment found in algae, yeast, and aquatic animals (Hussein et al., 2006), has been found to be effective against $H$. pylori-induced apoptosis in gastric epithelial cells. This inhibitory effect in gastric epithelial cells of the AGS line is produced by upregulation of phosphorylated AMPK, which in turn blocks mTOR activation, thereby activating Unc 51-like autophagy activating kinase 1 and inducing autophagosome formation by increasing the microtubule-associated protein expression of light chain 3B II (LC3B-II) (Lee et al., 2020).

\section{AUTOIMMUNE GASTRITIS}

\section{Pathophysiology}

Autoimmune gastritis (AIG) refers to a selective loss of parietal cells in the gastric mucosa due to autoimmune phenomenon. This condition is strongly associated with a severe form of vitamin B12-deficiency anemia, known as pernicious anemia, resulting from the increased $\mathrm{pH}$ of the stomach and a loss of intrinsic factors due to parietal cell destruction (De Block et al., 2000; Neumann et al., 2013). The pathophysiology of AIG is as yet poorly understood. Both the $\alpha$-subunit (catalytic) and $\beta$-subunit (glycoprotein) of the gastric proton pump $\mathrm{H}^{+} / \mathrm{K}^{+}$ ATPase, located on parietal cells, are the major target autoantigens recognized by anti-parietal cell antibodies (Callaghan 
et al., 1993). The $\mathrm{H}^{+} / \mathrm{K}^{+}$ATPase induces the proliferation of $\mathrm{CD}^{+} \mathrm{T}$ cell clones of the gastric mucosa, causing the production of tissue necrosis factor (TNF) and IFN- $\gamma$ by Th- 1 cells (D'Elios et al., 2001). Intrinsic factors, which are recognized by activated autoreactive CD4 ${ }^{+} T$ cells and activate cytotoxic $T$ cells against parietal cells, are secreted in the gastric mucosa of patients with AIG (Troilo et al., 2019). Recent studies have suggested that AIG is associated with changes in autophagy. IFN- $\gamma$ initiates autophagy in gastric epithelial cells by activating the transcription of Beclin-1 and increasing the expression levels of LC3-II (Tu et al., 2011).

\section{Therapeutic approaches}

Supplementation with micronutrients is essential in the management of AIG. Various oral iron supplements, including ferrous sulfate, ferrous fumarate, ferrous gluconate, ferrous glycine-sulfate, ferric protein-succinylate, ferric mannitolovalbumin, and ferric polymaltose complex, are available. These are used to overcome iron deficiency in patients with AIG (Pisani et al., 2015). Oral vitamin $B_{12}$ supplements are prescribed when pernicious anemia is present (Andres et al., 2010). Parenteral injection of vitamin $B_{12}$ is also important when neurological symptoms occur (Lenti et al., 2020). Additionally, eradication of $H$. pylori infection to decrease the levels of AIG-linked antibodies can be another therapeutic strategy, as co-infection with $H$. pylori is related to AIG (Stolte et al., 1998; Faller et al., 1999).

IFN- $\gamma$ is an important component of the type 1 immune response produced by activated CD4+ and CD8+ T cells (Billiau et al., 1998). Some studies have shown the potential role of IFN- $\gamma$ in the treatment of autoimmune gastritis. Overexpression of IFN- $\gamma$ reduces gastric inflammation by inducing autophagy and decreasing gastric epithelial cell apoptosis (Tu et al., 2011). Conversely, in a mouse model of autoimmune gastritis, depletion of IFN- $\gamma$ has positive outcomes in treating AIG because IFN- $\gamma$ acts directly on gastric epithelial cells and is necessary for the development from gastritis to atrophic gastritis and metaplasia (Osaki et al., 2019). Therefore, it is important to note that cytokines can have either antagonistic or synergistic effects during an immune response. The relevant mechanisms should be explored in more detail to determine the potential role of IFN- $\gamma$ in AIG prevention.

\section{AUTOPHAGY AND IBD}

\section{Pathophysiology}

IBD is a lifelong inflammatory disease of the GI tract. IBD encompasses Crohn's disease (CD), ulcerative colitis (UC), colonic IBD, and an unclassified type (IBDU). CD and UC are relatively common and can be considered the main subtypes of IBD. They differ in the extent of the affected site. In CD, submucosal or transmural inflammation and ulcers can be found at any location along the GI tract, whereas in UC, ulcers are localized to the colon and inflammation is limited to the mucosa and epithelial lining of the GI tract. The cause of IBD is not fully understood. In 2017, Choy et al. (2017) found that more than 160 genetic loci were associated with IBD; most of these are related to host immune response and microbial handling by the immune system. The disease is thought to be the result of an uncontrolled immune response to a trigger in genetically prone individuals, fueled by environmental factors
(Alatab et al., 2020).

By 2020, more than 200 genetic loci had been found by large-scale, genome-wide studies to be associated with IBD (Jairath and Feagan, 2020), some of which were also associated with autophagy (Massey and Parkes, 2007; Parkes et al., 2007; Rioux et al., 2007). The ATG ATG16L1 (autophagy related 16-like 1) and IRGM (immunity related GTPase M) are closely related to the occurrence and development of IBD (Massey and Parkes, 2007; Naser et al., 2012). ATG16L1 is involved in autophagosome formation; it also interacts with other key proteins such as ATG5 and ATG12. The IRGM gene is related to the processes of autophagy regulation, proinflammatory cytokine production, and apoptosis, and plays an important role in the body's immunity (Parkes et al., 2007). These genetic studies have given rise to a growing number of studies that aim to identify the connection between autophagy dysfunction and IBD pathogenesis.

Generally, the immune system of the body can be divided into three lines of defense. The first of these consists of structural barriers, such as the epithelium barrier in the intestine. The second line of defense includes the inflammatory response, involving antimicrobial proteins or phagocytic leukocytes. The third line of defense is adaptive immunity. According to several studies, autophagy has a direct impact on all three lines of defense in the intestinal tract.

Autophagy has been reported to enhance intestinal barrier function by downregulating the pore-forming tight junction protein claudin-2 through lysosomal degradation in Caco-2 intestinal epithelial cells (Nighot et al., 2015). Increased intestinal permeability caused by defective intestinal epithelium barrier function is a common diagnostic factor in active IBD patients (Hu et al., 2015; Chang et al., 2017) and the upregulation of claudin-2 has been reported to be associated with the disease (Luettig et al., 2015). Innate immune signaling pathways are initiated when microorganism-specific pathogen-associated molecular pattern molecules are recognized by host pattern recognition receptors (PRRs). PRRs, such as toll-like receptors (TLRs) and nucleotide oligomerization domain (NOD)-like receptors (NLRs), can regulate the autophagy pathway (Oh and Lee, 2014). NOD2, an NLR, was the first gene found to be associated with $C D$, and it remains one of the genetic factors that confer the greatest risk for the development of $C D$ (Philpott et al., 2014). Stimulation of NOD2 induces autophagy in dendritic cells in a receptor-interacting serine-threonine kinase 2-dependent manner (Cooney et al., 2010); stimulation of TLRs with their specific ligands has also been shown to stimulate autophagy (Delgado and Deretic, 2009). CD-associated NOD2 variants cannot recruit ATG16L1 to the plasma membrane at the bacterial entry site, thereby resulting in defective bacterial clearance (Fritz et al., 2011). Moreover, the combination of disease-associated alleles of ATG16L1 and NOD2/caspase recruitment domain-containing protein 15 has been shown to synergistically increase susceptibility to $C D$, indicating possible crosstalk between NOD2- and ATG16L1mediated processes in the pathogenesis of CD (BillmannBorn et al., 2011).

Furthermore, mutations in the ATG (ATG16L1, IRGM, and $N O D 2$ ) in intestinal epithelial cells may result in defective bacterial clearance. Abnormal morphology and autophagy dysfunction in Paneth cells are among the major outcomes of polymorphisms in ATG16L and IRGM, which are associated with IBD. Paneth cells are secretory epithelial cells found pre- 
dominantly in the intestinal crypts. Their function is to secrete antimicrobial peptides and immunomodulating proteins to regulate the intestinal microbiota, thereby providing protection to the intestinal stem cells that line the crypt walls (Lueschow and McElroy, 2020). It has been reported that Paneth cells are an original site for intestinal inflammation in diseases such as IBD (Wang et al., 2018a; Wehkamp and Stange, 2020). In both ATG16L1 mutant mice and IRGM1 knockout mice, impaired autophagy was seen, along with effects on both morphology and function of the Paneth cells; most notably, a marked alteration in the appearance of their secretory granules was observed (Cadwell et al., 2008; Liu et al., 2013). The impairment of ATG also allows adherent-invasive E. coli to replicate and survive, leading to CD progression (Lapaquette et al., 2010). Furthermore, increased expression of IRGM could reduce the inflammatory response by mediating selective autophagic degradation of inflammasomes targeting the NLR family pyrin domain 3 (NLRP3) and the adaptor molecule apoptosis-associated speck-like protein containing a CARD (ASC) (Mehto et al., 2019).

In addition to its essential role in innate immune defense against infection, autophagy plays a role in the adaptive immune response (Wang et al., 2018a). Autophagy contributes to the formation of antigenic peptides in antigen-presenting cells that link to $\mathrm{T}$ cells by means of major histocompatibility complex (MHC)-I or MHC-II to trigger an adaptive immune response (Henderson and Stevens, 2012). The dendritic cells from CD patients with risk-associated NOD2 and ATG16L1 variants are defective in autophagy induction and MHC class Il antigen presentation (Cooney et al., 2010).

\section{Therapeutic approaches}

A report of autophagy induction via mammalian target of rapamycin complex 1 (mTORC1) and the unfolded protein response (UPR) by the IBD drug azathioprine suggests that stimulation of autophagy and UPR may contribute to the therapeutic efficacy of a drug (Hooper et al., 2019). Azathio- prine is a commonly prescribed immunosuppressant in IBD and is used to maintain remission in moderate to severe $C D /$ UC (Retnakumar and Muller, 2019). Cyclosporine, another immunosuppressant drug used in IBD therapy, also induces autophagy (Ciechomska et al., 2013; Kim et al., 2014).

Some autophagy regulators have shown promising effects in IBD, and research into autophagy-related targets is growing. Metformin, which has been found to regulate autophagy (Nazim et al., 2016; Wang et al., 2018b), also ameliorates IBD (Chen et al., 2018). In a dextran sulfate sodium (DSS)induced murine colitis model, the mTOR inhibitor P2281 as well as torin1, were effective (Bhonde et al., 2008). Rapamycin, betanin, and trehalose induce autophagy and ameliorate intestinal inflammation and colitis by reversing the increased expression of M1 macrophage-associated markers (CC-chemokine receptor 7 , and clusters of differentiation $11 \mathrm{c}$ and 86 ), and pro-inflammatory cytokines (cyclooxygenase-2 and IL-6), as well as affecting NF-KB signaling, while increasing the levels of anti-inflammatory cytokine IL-10 in mice with 2,4,6-trinitrobenzene sulfonic acid (TNBS)-induced colitis (Macias-Ceja et al., 2017). In addition, rapamycin has been effective in clinical studies. In a case report of a 37-year old woman with severe refractory colonic and perianal $C D$, rapamycin (sirolimus) treatment produced marked and sustained improvements in symptoms and endoscopic appearance, after treatment with azathioprine, methotrexate, and infliximab failed (Massey et al., 2008). Another study has also provided evidence that sirolimus can be effective as a rescue therapy in a subgroup of children with severe IBD refractory to conventional therapies, by inducing both clinical remission and mucosal healing (Mutalib et al., 2014). Selected investigations from the past five years that demonstrate the promising nature of IBD therapies targeting autophagy, are described in Table 1.

Table 1. Recent laboratory findings indicating links between autophagy and IBD

\begin{tabular}{|c|c|c|}
\hline Treatment & Outcome & Reference \\
\hline Slit2/Robo1 & Activated autophagy in intestinal stem cells and mitigated DSS-induced UC & Xie et al., 2020 \\
\hline Dapagliflozin & $\begin{array}{l}\text { Increased colonic autophagy and suppressed apoptosis in a TNBS-induced rat } \\
\text { colitis model }\end{array}$ & Arab et al., 2021 \\
\hline TREM-1 inhibitor & Restored impaired autophagy and alleviated colitis in mice & Kokten et al., 2018 \\
\hline IL-33 & Reduced TNBS-induced colitis in mice by promoting mitophagy & Wang et al., 2019 \\
\hline Celastrol & $\begin{array}{l}\text { Augmented NLRP3 inhibitor (CP-456773) activity through heat shock protein-90 } \\
\text { and increased autophagy in rats with DSS-induced colitis }\end{array}$ & Saber et al., 2020 \\
\hline Curcumin & $\begin{array}{l}\text { Prevented the development of DSS-induced colitis in mice through inhibition of } \\
\text { excessive autophagy and regulation of the subsequent cytokine network }\end{array}$ & Yue et al., 2019 \\
\hline Herb-Partitioned Moxibustion & $\begin{array}{l}\text { Attenuated intestinal inflammation and promoted the repair of colon mucosal } \\
\text { injury in rats with CD while downregulating the autophagy-associated NOD2 } \\
\text { and IRGM genes }\end{array}$ & Zhao et al., 2019 \\
\hline Resveratrol & $\begin{array}{l}\text { Increased autophagosome levels, decreased inflammatory cytokine levels, and } \\
\text { alleviated UC-related intestinal mucosal barrier dysfunction in mice with DSS- } \\
\text { induced colitis }\end{array}$ & Pan et al., 2020 \\
\hline
\end{tabular}

Robo1, roundabout homolog 1; DSS, dextran sulfate sodium; UC, ulcerative colitis; TNBS, 2,4,6-trinitrobenzene sulfonic acid; TREM1, triggering receptor expressed on myeloid cells 1; IL-33, interleukin-33; NLRP3, NOD-, LRR-, and pyrin domain-containing protein 3; CD, Crohn's disease. 


\section{AUTOPHAGY AND GI CANCER}

\section{Pathophysiology}

In GI cancers, as in the general pathophysiology of cancer, once cells liable to cancer begin their neoplastic transformation, these genetically mutated oncogenic cells grow into abnormal shapes and divide uncontrollably and rapidly, yielding in-situ or malignant (invasive) tumors over time. GI cancers are those in which the neoplasms arise in any tissue of the GI tract or other organs involved in digestion, including the esophagus, stomach, biliary system, pancreas, small intestine, large intestine, rectum, and anus.

As a crucial homeostatic process, autophagy is increasingly recognized as an important factor in understanding and managing cancers. Mounting evidence highlights the complex and multifaceted role of autophagy in carcinogenesis (Folkerts et al., 2019). The neoplastic transformation in the early phase of carcinogenesis is associated with disruption of the autophagy process. This allows the accumulation of oncogenes and reactive oxygen species, thus favoring neoplasm formation. Correspondingly, blockading chaperone-mediated autophagy in fibroblasts has been shown to enhance the efficiency of cellular transformation driven by the proto-oncogene $\mathrm{MYC} / \mathrm{c}$ Myc (Gomes et al., 2017). In the same study, chaperone-mediated autophagy was reported to suppress c-Myc activity by promoting proteasomal degradation. Another study reported that an experimental frameshift mutation of the ATG UVRAG (UV radiation resistance-associated gene) in mice resulted in an increased inflammatory response and colitis-associated cancer (Quach et al., 2019). In addition, autophagy can selectively eliminate oncogenic pathogen infection (Sui et al., 2017). Chronic H. pylori infection is a well-known risk factor for gastric carcinogenesis. One effect of acute VacA exposure is the induction of xenophagy to counteract $H$. pylori infection. However, prolonged exposure to this toxin strongly disrupts xenophagy and promotes infection, eventually leading to gastric cancer (Greenfield and Jones, 2013). Correspondingly, individuals carrying the ATG polymorphism (ATG16L1 rs2241880 variant) have an increased risk of developing $H$. pylori infection and gastric cancer, indicating that a xenophagy defect may be associated with the initiation of gastric cancer (Castaño-Rodríguez et al., 2015).

Conversely, increased autophagic flux is common in established cancers, perhaps as an energy supply to cancer cells, contributing to their survival during stress (Folkerts et al., 2019). Autophagy could also maintain tumor stemness and enable leveling up to the metastasis stage. In addition, it also influences the metabolism of cancer cells. Cancer cells can perform glycolysis even in the presence of oxygen, known as the Warburg effect, to offset nutrient stress. Autophagy can control this aerobic glycolysis at different levels by selectively degrading the rate-limiting enzymes involved in the glycolytic pathway, such as pyruvate kinase muscle isozyme M2 (PKM2) (Lv et al., 2011) and hexokinase 2 (Jiao et al., 2018), resulting in the accumulation of glycolytic intermediates that re-enter various branching biosynthetic pathways to support cancer growth. Furthermore, the stem cells of multiple cancer types have been shown to express relatively high levels of essential genes, and autophagy inhibition could augment their chemosensitivity (Li et al., 2018; Nazio et al., 2019).

Notably, sensitivity to and tolerance of autophagy regulation vary with cancer stage and cellular conditions (Lauzier et al., 2019). In addition to protective autophagy, autophagic cell death can occur. This refers to cell death induced by the activation of autophagy flux alone, with no other types of programmed cell death involved (Jung et al., 2020). Cancer cells at risk of cell death could stimulate protective autophagy against the stress induced by chemotherapy, resulting in chemoresistance (Jing et al., 2020; Xu et al., 2020a). Conversely, direct and strong stimulation of autophagy by specific chemotherapies could induce autophagic cell death, highlighting the dual nature of autophagy. Autophagy itself can reverse chemoresistance by mediating apoptosis and/or inhibiting epithelial-mesenchymal transition (EMT) (Xu et al., 2020a). The outcome of the autophagy process varies depending on the stress level and stage of the cancer. Alterations in ATG have been found to be associated with tumorigenesis in $\mathrm{GI}$ cancers (Burada et al., 2015; Qian and Yang, 2016); these alterations are summarized as follows. Frameshift mutations in ATG2B, ATG5, ATG9B, and ATG12 are common in gastric cancers with high microsatellite instability, while other genes, such as ATG6/Beclin1, ATG8/LC3, p62/SQSTM1 (sequestosome-1), or SIRT1 (sirtuin-1), are often upregulated in GI cancers. Furthermore, higher expression of ATG10 is associated with tumor lymph node metastasis and poor survival in colorectal cancer (Choy et al., 2017). Additionally, researchers have reported that major ATG can be used as prognostic markers for Gl cancers, including esophageal, gastric, colon, and pancreatic cancers, as well as hepatocellular carcinoma (Mo et al., 2019; Wang et al., 2020a; Xu et al., 2020b; Yue et al., 2020; Du et al., 2021; Li et al., 2021).

\section{Therapeutic approaches}

Several clinical trials of autophagy-inhibiting anti-cancer treatments have been conducted and published. Currently, chloroquine (CQ) and hydroxychloroquine (HCQ) are the only drugs available for clinical use (Xu et al., 2018). A meta-analysis based on various types of cancer, including pancreatic cancer, showed that both $\mathrm{CQ}$ and $\mathrm{HCQ}$ can significantly improve the overall response rate (ORR), 1-year overall survival (OS) rate, and 6-month progression-free survival (PFS) rate. HCQ-based therapy produces better 1-year OS and 6-month PFS rates than CQ-based therapy, and CQ-based therapy produces better ORR than HCQ-based therapy (Xu et al., 2018). Some clinical trials published in the last seven years are described in Table 2. The clinical value of targeting autophagy with the HCQ therapy remains controversial.

Nevertheless, the laboratory investigations into drugs targeting or mediating autophagy in cancer therapy are attracting increased attention; novel compounds and pathways have been discovered. For instance, natural products, such as flavonoids, alkaloids, terpenoids, and coumarins, have been reported as potential autophagy inhibitors and activators and as agents reversing multidrug resistance in gastric cancer (Xu et al., 2020a). Furthermore, pectolinarigenin, which is a natural flavonoid present in Cirsium chanroenicum and citrus fruits, has been shown to induce autophagy- and apoptosis-related cell death in the AGS and MKN28 human gastric cancer cell lines (Lee et al., 2018). Chrysin from propolis also inhibits colorectal cancer to an extent comparable to inhibition by the 5-fluorouracil+oxaliplatin combination through autophagy induction (Lin et al., 2018). High PKM2 expression has been reported in GI cancers, including esophageal, gastric, colorectal, and liver types (Su et al., 2011; Wu et al., 2016; Wang et 
Table 2. Overview of phase I/II clinical trials in GI cancers with $\mathrm{HCQ}$

\begin{tabular}{|c|c|c|c|}
\hline Treatment & Cancer type & Outcome & Reference \\
\hline $\begin{array}{l}\mathrm{HCQ}+\text { Gemcitabine (Phase II } \\
\text { randomized) }\end{array}$ & $\begin{array}{l}\text { Metastatic pancreatic } \\
\text { adenocarcinoma }\end{array}$ & $\begin{array}{l}\text { Addition of hydroxychloroquine to chemotherapy did not } \\
\text { improve overall survival among patients with meta- } \\
\text { static pancreatic cancer, but significantly increased } \\
\text { the overall tumor response rate. }\end{array}$ & Karasic et al., 2019 \\
\hline $\begin{array}{l}\text { HCQ (Phase II and pharma- } \\
\text { codynamic study) }\end{array}$ & $\begin{array}{l}\text { Metastatic pancreatic } \\
\text { adenocarcinoma }\end{array}$ & $\begin{array}{l}\text { In patients with previously treated metastatic pancre- } \\
\text { atic cancer, } \mathrm{HCQ} \text { monotherapy achieved inconsistent } \\
\text { autophagy inhibition and demonstrated negligible } \\
\text { therapeutic efficacy. }\end{array}$ & Wolpin et al., 2014 \\
\hline $\begin{array}{l}\mathrm{HCQ}+\text { Gemcitabine (Phase II } \\
\text { randomized) }\end{array}$ & $\begin{array}{l}\text { Potentially resectable } \\
\text { pancreatic cancer }\end{array}$ & Improved pathologic and biomarker response. & Zeh et al., 2020 \\
\hline
\end{tabular}

$\mathrm{HCQ}$, hydroxychloroquine.

Table 3. Recent laboratory findings indicating links between autophagy and human GI cancers

\begin{tabular}{|c|c|c|c|}
\hline Treatments & Cancer type & Outcome & Reference \\
\hline $\operatorname{miR}-133 a-3 p$ & Gastric cancer & $\begin{array}{l}\text { Targeted GABARAPL1 to block autophagy-mediated glutaminolysis, } \\
\text { further repressing gastric cancer growth and metastasis }\end{array}$ & Zhang et al., 2018 \\
\hline $\begin{array}{l}\text { Caffeine and } \\
\text { theophylline }\end{array}$ & Gastric cancer & $\begin{array}{l}\text { Effectively induced gastric cancer cell apoptosis and autophagy by } \\
\text { PTEN activation and PI3K/AKT/mTOR pathway suppression }\end{array}$ & Liu et al., 2019 \\
\hline Berberine & Gastric cancer & $\begin{array}{l}\text { Repressed human gastric cancer cell growth in vitro and in vivo by } \\
\text { inducing cytostatic autophagy via inhibition of mitogen-activated } \\
\text { protein kinase /mTOR/70-kDa ribosomal protein S6 kinase and AKT }\end{array}$ & Zhang et al., 2020 \\
\hline Compound TDB & Gastric cancer & $\begin{array}{l}\text { Induced autophagy-dependent apoptosis by regulating PI3K/AKT/ } \\
\text { mTOR }\end{array}$ & Xiao et al., 2021 \\
\hline Trifolirhizin & Colorectal cancer & $\begin{array}{l}\text { Induced autophagy by activating the AMPK/mTOR pathway and posi- } \\
\text { tively contributed to extrinsic apoptosis both in vivo and in vitro }\end{array}$ & Sun et al., 2020 \\
\hline S130 (Atg4 inhibitor) & Colorectal cancer & $\begin{array}{l}\text { Significantly attenuated the growth of xenografted colorectal cancer } \\
\text { cells, especially when combined with caloric restriction }\end{array}$ & Fu et al., 2019 \\
\hline UBLA4 & $\begin{array}{l}\text { Pancreatic ductal } \\
\text { adenocarcinoma }\end{array}$ & Inhibited autophagy-mediated proliferation and metastasis & Chen et al., 2019 \\
\hline miR-18-5p & Pancreatic cancer & Inhibited autophagy by targeting SIRT1 & Tian et al., 2017 \\
\hline
\end{tabular}

GABARAPL1, gamma-aminobutyric acid receptor-associated protein-like 1; PTEN, phosphatase and tensin homolog; TDB, tricyclic decyl benzoxazole; UBLA4, ubiquitin-like protein 4A; SIRT1, sirtuin-1.

al., 2017). Overexpression of the PKM2 enzyme can block the autophagy process by activating mTORC1 (He et al., 2016). ATG7 has been shown to reduce the Warburg effect by blocking the binding of PKM2 to its upstream kinase fibroblast growth factor receptor 1 and thereby suppressing the phosphorylation of the PKM2 Tyr105 site, leading to reduced EMT in tumor cells (Feng et al., 2018). Inhibition of the PFKFB $_{3}$ glycolytic enzyme (6-phosphofructo-2-kinase/fructose-2,6biphosphatase 3 ) attenuates autophagy and increases the chemosensitivity of colorectal cancer cells to oxaliplatin treatment (Yan et al., 2019). Some new findings linking autophagy and $\mathrm{Gl}$ cancer therapy published in the last five years, are described in Table 3.

\section{AUTOPHAGY AND GASTROINTESTINAL MOTILITY DISORDERS}

\section{Pathophysiology}

Gastrointestinal smooth muscles generate rhythmic electrical pulses, resulting in cycles of contraction and relaxation (Sanders et al., 2012). Contractility is driven by the phosphorylation of myosin light chain 20 (MLC20) by $\mathrm{Ca}^{2+} /$ calmodulindependent myosin light chain kinase or $\mathrm{Ca}^{2+}$-independent kinases, including $\rho$-kinase, integrin-linked kinase, and zipperinteracting protein kinase. Relaxations are caused by the myosin light-chain phosphatase-containing myosin phosphatase target subunit, which dephosphorylates MLC20 (Somlyo and Somlyo, 2003; Ihara and MacDonald, 2007). Moreover, interstitial cells of Cajal (ICC) provide a pathway for the propagation of slow waves and are responsible for the motility pattern observed at the organ level (lino et al., 2009). ICCs depend on the SCF/c Kit interaction for growth and development and respond to its signaling by upregulating neurotransmission 
(Chai et al., 2017). Lack of ICC in the small intestine results in failure to generate pacemaker activity, leading to GI dysfunction in humans. ICC is, therefore, recognized as the pacemaker for the Gl tract (Huizinga et al., 1995; Burns, 2007; Farrugia, 2008).

Slow waves propagate via the depolarization-induced activation of voltage-dependent $\mathrm{Ca}^{2+}$ channels, facilitating $\mathrm{Ca}^{2+}$ entry into the $\mathrm{ICC}$ and inducing $\mathrm{Ca}^{2+}$ release (Sanders et al., 2012). The $\mathrm{Ca}^{2+} /$ calmodulin-dependent protein kinase 2-AMPK pathway induces autophagy following an increase in cytosolic $\mathrm{Ca}^{2+}$ levels (Ghislat et al., 2012). Consequently, excessive autophagy can disrupt the ICC, which largely depends on SCF/c-kit signaling, leading to GI dysmotility disorders such as slow transit constipation. Moreover, irritable bowel syndrome (IBS) is also linked to SCF/c-kit signaling, which is activated by a mild inflammatory response (Chai et al., 2017). In rats with functional dyspepsia, the AMPK/TSC2 (tuberous sclerosis complex 2)/Rheb signaling pathway is inactivated, and ghrelin levels in rat tissues are reduced. The mTOR inhibitor rapamycin accelerates the positive effect of electro-acupuncture in rats with functional dyspepsia (Tang et al., 2020). Inhibition of mTOR leads to the activation of au-

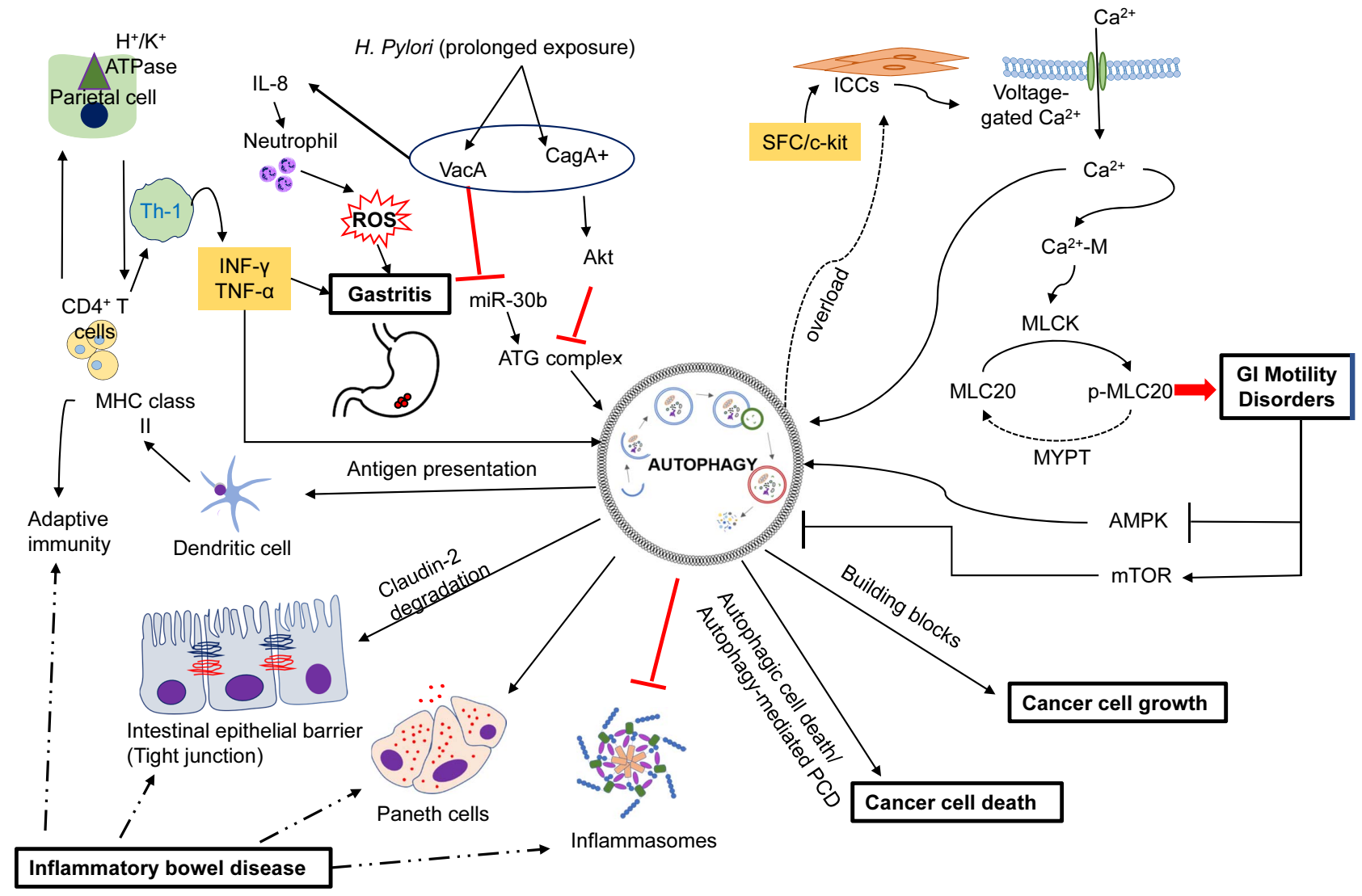

Fig. 1. Autophagy-related mechanisms of pathogenesis in gastrointestinal disorders. Virulence factors $\left(\right.$ VacA and CagA $\left.{ }^{+}\right)$from Helicobacter pylori cause the production of IL-8, which attracts neutrophils, thereby releasing reactive oxygen species (ROS). These attack the gastric mucosa, leading to chronic atrophic gastritis. The two virulence factors also block the autophagy process through the activation of AKT and inactivation of miR-30b, both of which regulate autophagy. When the dendritic cells in the gastric mucosa become activated, they cause the release of the proton pump $\mathrm{H}+/ \mathrm{K}+$ ATPase from the parietal cells. $\mathrm{H}+/ \mathrm{K}+$ ATPase is a major target for autoantigens during autoimmune activation. CD4+ T cells become activated in the presence of a proton pump and cause Th-1 cells to release INF- $\gamma$ and TNF- $\alpha$, thereby leading to autoimmune gastritis. INF- $\gamma$ and TNF- $\alpha$ activate the autophagy process. Autophagy stimulates dendritic cells through antigen presentation. MHC class II is activated by the adaptive immune system in inflammatory bowel disease (IBD). IBD causes intestinal epithelial barrier destruction via claudin-2 degradation, which originates from the activation of autophagy. Autophagy can cause impairment of Paneth cells, which are the primary site for intestinal inflammation in IBD. Autophagy degrades the inflammasomes that are released during IBD. During cancer cell growth and cell death, autophagy stimulates the building blocks for cancer pathogenesis and causes autophagic cell death. In addition, the SCF/c-kit propagates the slow waves through the ICCs, which increases the entry of $\mathrm{Ca}^{2+}$ into the cells. Ca ${ }^{2+}$ binds to calmodulin and causes smooth muscle contraction via activation of MLCK, which phosphorylates MLC20 to p-MLC20. Autophagy overload causes the destruction of ICCs and leads to gastrointestinal motility disorders, in which AMPK is decreased and mTOR is activated. The entire autophagy process is thus impaired, as is gastrointestinal homeostasis. GI, gastrointestinal; IL-8, interleukin 8; MHC class II, major histocompatibility complex class II; VacA, vacuolating cytotoxin A; CagA+, cytotoxin-associated gene A; INF- $\gamma$, interferon gamma; TNF- $\alpha$, tumor necrosis factor alpha; AKT, protein kinase B; SCF, stem cell factor; ICCs, interstitial cells of Cajal; $\mathrm{Ca}^{2+}-\mathrm{M}$, calcium calmodulin complex; MLCK, myosin light chain kinase; MLC20, myosin light chain 20; p-MLC, phosphorylated myosin light chain 20; MYPT, myosin light chain phosphatase; mTOR, mammalian target of rapamycin; AMPK, 5' adenosine monophosphate-activated protein kinase; Th-1, helper T cell 1; ATG, autophagy-related genes. 
tophagy. Therefore, it can be assumed that autophagy plays an important role in functional dyspepsia.

\section{Therapeutic approaches}

Drugs targeting SCF/c-kit inhibition are potential treatments for the management of IBS due to autophagy. Pharmacological antagonists for SCF/c-kit signaling include imatinib, lapatinib, sunitinib, imatinib, and sorafenib. However, the use of these inhibitors is limited because blocking SCF/c-kit signaling may worsen the tissue damage (Milenkovic et al., 2007). Therefore, further research is needed to identify the detailed mechanisms, and to explore the efficacy and safety of the use of these inhibitors in IBS therapy.

In addition, some complementary and alternative medicines have beneficial effects in other GI disorders. Tong bian decoction, a Chinese medicinal herb, exerts a laxative effect in rats with slow transit constipation by inhibiting autophagy in the ICC, which in turn promotes its regeneration and repair abilities (Zhou et al., 2020). Applying electro-acupuncture in rats with functional dyspepsia increases their ghrelin levels and activates AMPK/TSC2/Rheb signaling by inhibiting mTOR, leading to the amelioration of dyspepsia (Tang et al., 2020).

Zhi Shi Xiao Pi Tang (ZSXPT), a Chinese traditional medicine formulation, consists of ten medicinal plants: immature bitter orange, Magnolia officinalis, coptis, Pinellia ternate, ginger rhizome, malt, rhizoma atractylodis macrocephalae, Poria cocos, Codonopsis pilosula, and liquorice. Pretreatment with ZSXPT in rats with functional dyspepsia accelerates autophagy and inhibits ROS generation and subsequent apoptosis via the blockade of mTOR signaling. The efficacy and safety of these medicinal herbs for treating functional dyspepsia should be further investigated.

\section{CONCLUSION AND FUTURE DIRECTIONS}

A number of factors must be considered in future studies. Firstly, the signaling pathway of autophagy can influence neighboring proteins for different purposes under certain circumstances. Secondly, as the original purpose of autophagy is homeostasis, it should be noted that all ATG also exist in normal cells, not only in the abnormal cells of our target. Thirdly, the known autophagy regulators therefore also have offtarget or autophagy-independent effects and lack specificity to any particular cell type. Fourthly, our understanding of GI disease etiology is still incomplete, especially in IBD and cancer. Importantly, the IBD-associated ATG variants are also found in healthy individuals, and their presence alone is not sufficient to induce IBD. Fifthly, autophagy itself is flexible and varies in the different levels of stimuli it accepts; the outcome of the autophagic process may be beneficial or deleterious to the host cells. Therefore, logically, the development of novel strategies or compounds to precisely modulate the specific autophagic processes that are pathologically defective, without interfering with other autophagy processes, or the development of efficient personalized approaches depending on the specific pathological conditions, should form the basis of future research. Furthermore, studies enabling a clear understanding of the molecular mechanisms underlying the connection between autophagy and GI diseases are needed. The summary of the pathogenesis mechanisms of autophagy on disorders is provided in the Fig. 1.

\section{ACKNOWLEDGMENTS}

This research was supported by the Basic Science Research Program through the National Research Foundation of Korea (NRF), funded by the Ministry of Education, Science, and Technology [Grant NRF-2019R1F1A1062070].

\section{REFERENCES}

Alatab, S., Sepanlou, S. G., Ikuta, K., Vahedi, H., Bisignano, C., Safiri, S., Sadeghi, A., Nixon, M. R., Abdoli, A., Abolhassani, H., Alipour, V., Almadi, M. A. H., Almasi-Hashiani, A., Anushiravani, A., Arabloo, J., Atique, S., Awasthi, A., Badawi, A., Baig, A. A. A., Bhala, N., Bijani, A., Biondi, A., Borzì, A. M., Burke, K. E., Carvalho, F., Daryani, A., Dubey, M., Eftekhari, A., Fernandes, E., Fernandes, J. C., Fischer, F., Haj-Mirzaian, A., Haj-Mirzaian, A., Hasanzadeh, A., Hashemian, M., Hay, S. I., Hoang, C. L., Househ, M., Ilesanmi, O. S., Jafari Balalami, N., James, S. L., Kengne, A. P., Malekzadeh, M. M., Merat, S., Meretoja, T. J., Mestrovic, T., Mirrakhimov, E. M., Mirzaei, H., Mohammad, K. A., Mokdad, A. H., Monasta, L., Negoi, I., Nguyen, T. H., Nguyen, C. T., Pourshams, A., Poustchi, H., Rabiee, M., Rabiee, N., Ramezanzadeh, K., Rawaf, D. L., Rawaf, S., Rezaei, N., Robinson, S. R., Ronfani, L., Saxena, S., Sepehrimanesh, M., Shaikh, M. A., Sharafi, Z., Sharif, M., Siabani, S., Sima, A. R., Singh, J. A., Soheili, A., Sotoudehmanesh, R., Suleria, H. A. R., Tesfay, B. E., Tran, B., Tsoi, D., Vacante, M., Wondmieneh, A. B., Zarghi, A., Zhang, Z. J., Dirac, M., Malekzadeh, R. and Naghavi, M. (2020) The global, regional, and national burden of inflammatory bowel disease in 195 countries and territories, 1990-2017: a systematic analysis for the Global Burden of Disease Study 2017. Lancet Gastroenterol. Hepatol. 5, 17-30.

Andres, E., Fothergill, H. and Mecili, M. (2010) Efficacy of oral cobalamin (vitamin B12) therapy. Expert. Opin. Pharmacother. 11, 249-256.

Arab, H. H., Al-Shorbagy, M. Y. and Saad, M. A. (2021) Activation of autophagy and suppression of apoptosis by dapagliflozin attenuates experimental inflammatory bowel disease in rats: targeting AMPK/mTOR, HMGB1/RAGE and Nrf2/HO-1 pathways. Chem. Biol. Interact. 335, 109368.

Bhonde, M. R., Gupte, R. D., Dadarkar, S. D., Jadhav, M. G., Tannu, A. A., Bhatt, P., Bhatia, D. R., Desai, N. K., Deore, V., Yewalkar, N., Vishwakarma, R. A., Sharma, S., Kumar, S. and Dagia, N. M. (2008) A novel mTOR inhibitor is efficacious in a murine model of colitis. Am. J. Physiol. Gastrointest. Liver Physiol. 295, G1237G1245.

Billiau, A., Heremans, H., Vermeire, K. and Matthys, P. (1998) Immunomodulatory properties of interferon-gamma. An update. Ann. N. Y. Acad. Sci. 856, 22-32.

Billmann-Born, S., Lipinski, S., Böck, J., Till, A., Rosenstiel, P. and Schreiber, S. (2011) The complex interplay of NOD-like receptors and the autophagy machinery in the pathophysiology of Crohn disease. Eur. J. Cell Biol. 90, 593-602.

Boya, P., Reggiori, F. and Codogno, P. (2013) Emerging regulation and functions of autophagy. Nat. Cell Biol. 15, 713-720.

Burada, F., Nicoli, E. R., Ciurea, M. E., Uscatu, D. C., Ioana, M. and Gheonea, D. I. (2015) Autophagy in colorectal cancer: an important switch from physiology to pathology. World J. Gastrointest. Oncol. 7, 271-284.

Burns, A. J. (2007) Disorders of interstitial cells of Cajal. J. Pediatr. Gastroenterol. Nutr. 45, S103-S106.

Cadwell, K., Liu, J. Y., Brown, S. L., Miyoshi, H., Loh, J., Lennerz, J. K., Kishi, C., Kc, W., Carrero, J. A., Hunt, S., Stone, C. D., Brunt, E. M., Xavier, R. J., Sleckman, B. P., Li, E., Mizushima, N., Stappenbeck, T. S. and Virgin, H. W., 4th (2008) A key role for autophagy and the autophagy gene Atg16I1 in mouse and human intestinal Paneth cells. Nature 456, 259-263.

Callaghan, J. M., Khan, M. A., Alderuccio, F., van Driel, I. R., Gleeson, P. A. and Toh, B. H. (1993) Alpha and beta subunits of the gastric $\mathrm{H}+/ \mathrm{K}(+)$-ATPase are concordantly targeted by parietal cell auto- 
antibodies associated with autoimmune gastritis. Autoimmunity 16 289-295.

Carneiro, F., Fonseca, E. and Sobrinho-Simoes, M. (1992) Epithelial degeneration induced by Helicobacter pylori. Hum. Pathol. 23, 1314-1315

Castaño-Rodríguez, N., Kaakoush, N. O., Goh, K. L., Fock, K. M. and Mitchell, H. M. (2015) Autophagy in Helicobacter pylori infection and related gastric cancer. Helicobacter 20, 353-369

Chai, Y., Huang, Y., Tang, H., Tu, X., He, J., Wang, T., Zhang, Q., Xiong, F., Li, D. and Qiu, Z. (2017) Role of stem cell growth factor/ c-Kit in the pathogenesis of irritable bowel syndrome. Exp. Ther. Med. 13, 1187-1193.

Chang, J., Leong, R. W., Wasinger, V. C., Ip, M., Yang, M. and Phan, T. G. (2017) Impaired intestinal permeability contributes to ongoing bowel symptoms in patients with inflammatory bowel disease and mucosal healing. Gastroenterology 153, 723-731.e1.

Chen, H., Li, L., Hu, J., Zhao, Z., Ji, L., Cheng, C., Zhang, G., Zhang, T., Li, Y., Chen, H., Pan, S. and Sun, B. (2019) UBL4A inhibits autophagy-mediated proliferation and metastasis of pancreatic ductal adenocarcinoma via targeting LAMP1. J. Exp. Clin. Cancer Res. 38, 297.

Chen, L., Wang, J., You, Q., He, S., Meng, Q., Gao, J., Wu, X., Shen, Y., Sun, Y., Wu, X. and Xu, Q. (2018) Activating AMPK to restore tight junction assembly in intestinal epithelium and to attenuate experimental colitis by metformin. Front. Pharmacol. 9, 761.

Chey, W. D., Leontiadis, G. I., Howden, C. W. and Moss, S. F. (2017) ACG clinical guideline: treatment of Helicobacter pylori infection. Am. J. Gastroenterol. 112, 212-239.

Choy, M. C., Visvanathan, K. and De Cruz, P. (2017) An overview of the innate and adaptive immune system in inflammatory bowel disease. Inflamm. Bowel Dis. 23, 2-13.

Ciechomska, I. A., Gabrusiewicz, K., Szczepankiewicz, A. A. and Kaminska, B. (2013) Endoplasmic reticulum stress triggers autophagy in malignant glioma cells undergoing cyclosporine A-induced cell death. Oncogene 32, 1518-1529.

Cooney, R., Baker, J., Brain, O., Danis, B., Pichulik, T., Allan, P., Ferguson, D. J. P., Campbell, B. J., Jewell, D. and Simmons, A. (2010) NOD2 stimulation induces autophagy in dendritic cells influencing bacterial handling and antigen presentation. Nat. Med. 16, 90-97.

Correa, P. (1988) Chronic gastritis: a clinico-pathological classification. Am. J. Gastroenterol. 83, 504-509.

D'Elios, M. M., Bergman, M. P., Azzurri, A., Amedei, A., Benagiano, M., De Pont, J. J., Cianchi, F., Vandenbroucke-Grauls, C. M., Romagnani, S., Appelmelk, B. J. and Del Prete, G. (2001) H(+),K(+)atpase (proton pump) is the target autoantigen of Th1-type cytotoxic T cells in autoimmune gastritis. Gastroenterology 120, 377-386.

De Block, C. E., Van Campenhout, C. M., De Leeuw, I. H., Keenoy, B. M., Martin, M., Van Hoof, V. and Van Gaal, L. F. (2000) Soluble transferrin receptor level: a new marker of iron deficiency anemia, a common manifestation of gastric autoimmunity in type 1 diabetes. Diabetes Care 23, 1384-1388.

Delgado, M. A. and Deretic, V. (2009) Toll-like receptors in control of immunological autophagy. Cell Death Differ. 16, 976-983.

Du, H., Xie, S., Guo, W., Che, J., Zhu, L., Hang, J. and Li, H. (2021) Development and validation of an autophagy-related prognostic signature in esophageal cancer. Ann. Transl. Med. 9, 317.

Faller, G., Winter, M., Steininger, H., Lehn, N., Meining, A., Bayerdorffer, E. and Kirchner, T. (1999) Decrease of antigastric autoantibodies in Helicobacter pylori gastritis after cure of infection. Pathol. Res. Pract. 195, 243-246.

Farrugia, G. (2008) Interstitial cells of Cajal in health and disease. Neurogastroenterol. Motil. 20 Suppl 1, 54-63.

Feng, Y., Liu, J., Guo, W., Guan, Y., Xu, H., Guo, Q., Song, X., Yi, F., Liu, T., Zhang, W., Dong, X., Cao, L. L., O'Rourke, B. P. and Cao, L. (2018) Atg7 inhibits Warburg effect by suppressing PKM2 phosphorylation resulting reduced epithelial-mesenchymal transition. Int. J. Biol. Sci. 14, 775-783.

Folkerts, H., Hilgendorf, S., Vellenga, E., Bremer, E. and Wiersma, V. R. (2019) The multifaceted role of autophagy in cancer and the microenvironment. Med. Res. Rev. 39, 517-560.

Fritz, T., Niederreiter, L., Adolph, T., Blumberg, R. S. and Kaser, A. (2011) Crohn's disease: NOD2, autophagy and ER stress con- verge. Gut 60, 1580-1588.

Fu, Y., Hong, L., Xu, J., Zhong, G., Gu, Q., Gu, Q., Guan, Y., Zheng, X., Dai, Q., Luo, X., Liu, C., Huang, Z., Yin, X. M., Liu, P. and Li, M. (2019) Discovery of a small molecule targeting autophagy via ATG4B inhibition and cell death of colorectal cancer cells in vitro and in vivo. Autophagy 15, 295-311.

Ghislat, G., Patron, M., Rizzuto, R. and Knecht, E. (2012) Withdrawal of essential amino acids increases autophagy by a pathway involving $\mathrm{Ca} 2+/$ calmodulin-dependent kinase kinase-beta (CaMKK-beta). J. Biol. Chem. 287, 38625-38636.

Gomes, L. R., Menck, C. F. M. and Cuervo, A. M. (2017) Chaperonemediated autophagy prevents cellular transformation by regulating MYC proteasomal degradation. Autophagy 13, 928-940.

Greenfield, L. K. and Jones, N. L. (2013) Modulation of autophagy by Helicobacter pylori and its role in gastric carcinogenesis. Trends Microbiol. 21, 602-612.

Hardbower, D. M., Peek, R. M., Jr. and Wilson, K. T. (2014) At the Bench: Helicobacter pylori, dysregulated host responses, DNA damage, and gastric cancer. J. Leukoc. Biol. 96, 201-212.

He, C. L., Bian, Y. Y., Xue, Y., Liu, Z. X., Zhou, K. Q., Yao, C. F., Lin, Y., Zou, H. F., Luo, F. X., Qu, Y. Y., Zhao, J. Y., Ye, M. L., Zhao, S. M. and Xu, W. (2016) Pyruvate kinase M2 activates mTORC1 by phosphorylating AKT1S1. Sci. Rep. 6, 21524.

Henderson, P. and Stevens, C. (2012) The role of autophagy in Crohn's disease. Cells 1, 492-519.

Hooper, K. M., Casanova, V., Kemp, S., Staines, K. A., Satsangi, J., Barlow, P. G., Henderson, P. and Stevens, C. (2019) The inflammatory bowel disease drug azathioprine induces autophagy via mTORC1 and the unfolded protein response sensor PERK. Inflamm. Bowel Dis. 25, 1481-1496.

Hu, C. A. A., Hou, Y., Yi, D., Qiu, Y., Wu, G., Kong, X. and Yin, Y. (2015) Autophagy and tight junction proteins in the intestine and intestinal diseases. Anim. Nutr. 1, 123-127.

Huizinga, J. D., Thuneberg, L., Kluppel, M., Malysz, J., Mikkelsen, H. B. and Bernstein, A. (1995) W/kit gene required for interstitial cells of Cajal and for intestinal pacemaker activity. Nature 373, 347-349.

Hussein, G., Sankawa, U., Goto, H., Matsumoto, K. and Watanabe, H. (2006) Astaxanthin, a carotenoid with potential in human health and nutrition. J. Nat. Prod. 69, 443-449.

Ihara, E. and MacDonald, J. A. (2007) The regulation of smooth muscle contractility by zipper-interacting protein kinase. Can. J. Physiol. Pharmacol. 85, 79-87.

lino, S., Horiguchi, K., Nojyo, Y., Ward, S. M. and Sanders, K. M. (2009) Interstitial cells of Cajal contain signalling molecules for transduction of nitrergic stimulation in guinea pig caecum. Neurogastroenterol. Motil. 21, 542-550, e12-e13.

International Agency for Research on Cancer (1994) Schistosomes, Liver Flukes and Helicobacter pylori. World Health Organization.

Jairath, V. and Feagan, B. G. (2020) Global burden of inflammatory bowel disease. Lancet Gastroenterol. Hepatol. 5, 2-3.

Jiao, L., Zhang, H. L., Li, D. D., Yang, K. L., Tang, J., Li, X., Ji, J., Yu, Y., Wu, R. Y., Ravichandran, S., Liu, J. J., Feng, G. K., Chen, M. S., Zeng, Y. X., Deng, R. and Zhu, X. F. (2018) Regulation of glycolytic metabolism by autophagy in liver cancer involves selective autophagic degradation of HK2 (hexokinase 2). Autophagy 14, 671-684.

Jing, Y., Liang, W., Liu, J., Zhang, L., Wei, J., Yang, J., Zhang, Y. and Huang, Z. (2020) Autophagy-mediating microRNAs in cancer chemoresistance. Cell Biol. Toxicol. 36, 517-536.

Jung, S., Jeong, H. and Yu, S. W. (2020) Autophagy as a decisive process for cell death. Exp. Mol. Med. 52, 921-930.

Karasic, T. B., O'Hara, M. H., Loaiza-Bonilla, A., Reiss, K. A., Teitelbaum, U. R., Borazanci, E., De Jesus-Acosta, A., Redlinger, C., Burrell, J. A., Laheru, D. A., Von Hoff, D. D., Amaravadi, R. K., Drebin, J. A. and O'Dwyer, P. J. (2019) Effect of gemcitabine and nab-paclitaxel with or without hydroxychloroquine on patients with advanced pancreatic cancer: a phase 2 randomized clinical trial. JAMA Oncol. 5, 993-998.

Khamri, W., Walker, M. M., Clark, P., Atherton, J. C., Thursz, M. R., Bamford, K. B., Lechler, R. I. and Lombardi, G. (2010) Helicobacter pylori stimulates dendritic cells to induce interleukin-17 expression from CD4+ T lymphocytes. Infect. Immun. 78, 845-853.

Kim, H. S., Choi, S. I., Jeung, E. B. and Yoo, Y. M. (2014) Cyclosporine 
A induces apoptotic and autophagic cell death in rat pituitary $\mathrm{GH} 3$ cells. PLOS ONE 9, e108981.

Klionsky, D. J. (2005) The molecular machinery of autophagy: unanswered questions. J. Cell Sci. 118, 7-18.

Klionsky, D. J. (2007) Autophagy: from phenomenology to molecular understanding in less than a decade. Nat. Rev. Mol. Cell Biol. 8, 931-937.

Kokten, T., Gibot, S., Lepage, P., D’Alessio, S., Hablot, J., Ndiaye, N. C., Busby-Venner, H., Monot, C., Garnier, B., Moulin, D., Jouzeau, J. Y., Hansmannel, F., Danese, S., Gueant, J. L., Muller, S. and Peyrin-Biroulet, L. (2018) TREM-1 inhibition restores impaired autophagy activity and reduces colitis in mice. J. Crohns Colitis 12, 230-244.

Lapaquette, P., Glasser, A. L., Huett, A., Xavier, R. J. and DarfeuilleMichaud, A. (2010) Crohn's disease-associated adherent-invasive E. coli are selectively favoured by impaired autophagy to replicate intracellularly. Cell. Microbiol. 12, 99-113.

Lauzier, A., Normandeau-Guimond, J., Vaillancourt-Lavigueur, V., Boivin, V., Charbonneau, M., Rivard, N., Scott, M. S., Dubois, C. M. and Jean, S. (2019) Colorectal cancer cells respond differentially to autophagy inhibition in vivo. Sci. Rep. 9, 11316.

Lee, H., Lim, J. W. and Kim, H. (2020) Effect of astaxanthin on activation of autophagy and inhibition of apoptosis in Helicobacter pyloriinfected gastric epithelial cell line AGS. Nutrients 12, 1750.

Lee, H. J., Venkatarame Gowda Saralamma, V., Kim, S. M., Ha, S. E., Raha, S., Lee, W. S., Kim, E. H., Lee, S. J., Heo, J. D. and Kim, G. S. (2018) Pectolinarigenin induced cell cycle arrest, autophagy, and apoptosis in gastric cancer cell via PI3K/AKT/mTOR signaling pathway. Nutrients 10, 1043.

Lee, Y. C., Chiang, T. H., Chou, C. K., Tu, Y. K., Liao, W. C., Wu, M. S. and Graham, D. Y. (2016) Association between Helicobacter pylori eradication and gastric cancer incidence: a systematic review and meta-analysis. Gastroenterology 150, 1113-1124.e5.

Lenti, M. V., Rugge, M., Lahner, E., Miceli, E., Toh, B. H., Genta, R. M., De Block, C., Hershko, C. and Di Sabatino, A. (2020) Autoimmune gastritis. Nat. Rev. Dis. Primers 6, 56.

Leung, K. M., Hui, P. K., Chan, W. Y. and Thomas, T. M. (1992) Helicobacter pylori-related gastritis and gastric ulcer. A continuum of progressive epithelial degeneration. Am. J. Clin. Pathol. 98, 569-574.

Li, G. M., Li, L., Li, M. Q., Chen, X., Su, Q., Deng, Z. J., Liu, H. B., Li, B., Zhang, W. H., Jia, Y. X., Wang, W. J., Ma, J. Y., Zhang, H. L., Xie, D., Zhu, X. F., He, Y. L., Guan, X. Y. and Bi, J. (2021) DAPK3 inhibits gastric cancer progression via activation of ULK1-dependent autophagy. Cell Death Differ. 28, 952-967.

Li, L. Q., Pan, D., Zhang, S. W., D., Y. X., Zheng, X. L. and Chen, H. (2018) Autophagy regulates chemoresistance of gastric cancer stem cells via the Notch signaling pathway. Eur. Rev. Med. Pharmacol. Sci. 22, 3402-3407.

Li, N., Tang, B., Jia, Y. P., Zhu, P., Zhuang, Y., Fang, Y., Li, Q., Wang, K., Zhang, W. J., Guo, G., Wang, T. J., Feng, Y. J., Qiao, B., Mao, X. H. and Zou, Q. M. (2017) Helicobacter pylori CagA protein negatively regulates autophagy and promotes inflammatory response via c-Met-PI3K/Akt-mTOR signaling pathway. Front. Cell. Infect. Microbiol. 7, 417.

Lin, Y. M., Chen, C. I., Hsiang, Y. P., Hsu, Y. C., Cheng, K. C., Chien, P. H., Pan, H. L., Lu, C. C. and Chen, Y. J. (2018) Chrysin attenuates cell viability of human colorectal cancer cells through autophagy induction unlike 5-fluorouracil/oxaliplatin. Int. J. Mol. Sci. 19, 1763.

Liu, B., Gulati, A. S., Cantillana, V., Henry, S. C., Schmidt, E. A., Daniell, X., Grossniklaus, E., Schoenborn, A. A., Sartor, R. B. and Taylor, G. A. (2013) Irgm1-deficient mice exhibit Paneth cell abnormalities and increased susceptibility to acute intestinal inflammation. Am. J. Physiol. Gastrointest. Liver Physiol. 305, G573-G584.

Liu, H., Song, J., Zhou, Y., Cao, L., Gong, Y., Wei, Y., Yang, H. and Tang, L. (2019) Methylxanthine derivatives promote autophagy in gastric cancer cells targeting PTEN. Anticancer Drugs 30, 347355.

Lueschow, S. R. and McElroy, S. J. (2020) The Paneth cell: the curator and defender of the immature small intestine. Front. Immunol. $11,587$.

Luettig, J., Rosenthal, R., Barmeyer, C. and Schulzke, J. D. (2015) Claudin-2 as a mediator of leaky gut barrier during intestinal inflam- mation. Tissue Barriers 3, e977176.

Lv, L., Li, D., Zhao, D., Lin, R., Chu, Y., Zhang, H., Zha, Z., Liu, Y., Li, Z., Xu, Y., Wang, G., Huang, Y., Xiong, Y., Guan, K. L. and Lei, Q. Y. (2011) Acetylation targets the $M 2$ isoform of pyruvate kinase for degradation through chaperone-mediated autophagy and promotes tumor growth. Mol. Cell 42, 719-730.

Mabe, K., Yamada, M., Oguni, I. and Takahashi, T. (1999) In vitro and in vivo activities of tea catechins against Helicobacter pylori. Antimicrob. Agents Chemother. 43, 1788-1791.

Macias-Ceja, D. C., Cosín-Roger, J., Ortiz-Masiá, D., Salvador, P., Hernández, C., Esplugues, J. V., Calatayud, S. and Barrachina, M. D. (2017) Stimulation of autophagy prevents intestinal mucosal inflammation and ameliorates murine colitis. Br. J. Pharmacol. 174, 2501-2511.

Maes, H., Rubio, N., Garg, A. D. and Agostinis, P. (2013) Autophagy: shaping the tumor microenvironment and therapeutic response. Trends Mol. Med. 19, 428-446.

Malfertheiner, P., Megraud, F., O’Morain, C. A., Gisbert, J. P., Kuipers, E. J., Axon, A. T., Bazzoli, F., Gasbarrini, A., Atherton, J., Graham, D. Y., Hunt, R., Moayyedi, P., Rokkas, T., Rugge, M., Selgrad, M., Suerbaum, S., Sugano, K. and El-Omar, E. M.; European Helicobacter and Microbiota Study Group and Consensus panel (2017) Management of Helicobacter pylori infection-the Maastricht V/Florence Consensus Report. Gut 66, 6-30.

Marshall, B. J. and Warren, J. R. (1984) Unidentified curved bacilli in the stomach of patients with gastritis and peptic ulceration. Lancet 1, 1311-1315

Massey, D. C., Bredin, F. and Parkes, M. (2008) Use of sirolimus (rapamycin) to treat refractory Crohn's disease. Gut 57, 1294-1296.

Massey, D. C. and Parkes, M. (2007) Genome-wide association scanning highlights two autophagy genes, ATG16L1 and IRGM, as being significantly associated with Crohn's disease. Autophagy 3, 649-651.

Mehto, S., Jena, K. K., Nath, P., Chauhan, S., Kolapalli, S. P., Das, S. K., Sahoo, P. K., Jain, A., Taylor, G. A. and Chauhan, S. (2019) The Crohn's disease risk factor IRGM limits NLRP3 inflammasome activation by impeding its assembly and by mediating its selective autophagy. Mol. Cell 73, 429-445.e7.

Milenkovic, N., Frahm, C., Gassmann, M., Griffel, C., Erdmann, B., Birchmeier, C., Lewin, G. R. and Garratt, A. N. (2007) Nociceptive tuning by stem cell factor/c-Kit signaling. Neuron 56, 893-906.

Mizushima, N. (2018) A brief history of autophagy from cell biology to physiology and disease. Nat. Cell Biol. 20, 521-527.

Mo, S., Dai, W., Xiang, W., Li, Y., Feng, Y., Zhang, L., Li, Q. and Cai, G. (2019) Prognostic and predictive value of an autophagy-related signature for early relapse in stages I-III colon cancer. Carcinogenesis 40, 861-870.

Mutalib, M., Borrelli, O., Blackstock, S., Kiparissi, F., Elawad, M., Shah, N. and Lindley, K. (2014) The use of sirolimus (rapamycin) in the management of refractory inflammatory bowel disease in children. J. Crohns Colitis 8, 1730-1734.

Naser, S. A., Arce, M., Khaja, A., Fernandez, M., Naser, N., Elwasila, S. and Thanigachalam, S. (2012) Role of ATG16L, NOD2 and IL23R in Crohn's disease pathogenesis. World J. Gastroenterol. $18,412-424$.

Nazim, U. M., Moon, J. H., Lee, J. H., Lee, Y. J., Seol, J. W., Eo, S. K., Lee, J. H. and Park, S. Y. (2016) Activation of autophagy flux by metformin downregulates cellular FLICE-like inhibitory protein and enhances TRAIL- induced apoptosis. Oncotarget 7, 23468-23481.

Nazio, F., Bordi, M., Cianfanelli, V., Locatelli, F. and Cecconi, F. (2019) Autophagy and cancer stem cells: molecular mechanisms and therapeutic applications. Cell Death Differ. 26, 690-702.

Neumann, W. L., Coss, E., Rugge, M. and Genta, R. M. (2013) Autoimmune atrophic gastritis--pathogenesis, pathology and management. Nat. Rev. Gastroenterol. Hepatol. 10, 529-541.

Nighot, P. K., Hu, C. A. and Ma, T. Y. (2015) Autophagy enhances intestinal epithelial tight junction barrier function by targeting claudin-2 protein degradation. J. Biol. Chem. 290, 7234-7246.

Oh, J. E. and Lee, H. K. (2014) Pattern recognition receptors and autophagy. Front. Immunol. 5, 300.

Osaki, L. H., Bockerstett, K. A., Wong, C. F., Ford, E. L., Madison, B. B., DiPaolo, R. J. and Mills, J. C. (2019) Interferon-gamma directly 
induces gastric epithelial cell death and is required for progression to metaplasia. J. Pathol. 247, 513-523.

Pan, H. H., Zhou, X. X., Ma, Y. Y., Pan, W. S., Zhao, F., Yu, M. S. and Liu, J. Q. (2020) Resveratrol alleviates intestinal mucosal barrier dysfunction in dextran sulfate sodium-induced colitis mice by enhancing autophagy. World J. Gastroenterol. 26, 4945-4959.

Parkes, M., Barrett, J. C., Prescott, N. J., Tremelling, M., Anderson, C. A., Fisher, S. A., Roberts, R. G., Nimmo, E. R., Cummings, F. R., Soars, D., Drummond, H., Lees, C. W., Khawaja, S. A., Bagnall, R., Burke, D. A., Todhunter, C. E., Ahmad, T., Onnie, C. M., McArdle, W., Strachan, D., Bethel, G., Bryan, C., Lewis, C. M., Deloukas, P., Forbes, A., Sanderson, J., Jewell, D. P., Satsangi, J., Mansfield, J. C., Cardon, L. and Mathew, C. G. (2007) Sequence variants in the autophagy gene IRGM and multiple other replicating loci contribute to Crohn's disease susceptibility. Nat. Genet. 39, 830-832.

Philpott, D. J., Sorbara, M. T., Robertson, S. J., Croitoru, K. and Girardin, S. E. (2014) NOD proteins: regulators of inflammation in health and disease. Nat. Rev. Immunol. 14, 9-23.

Pisani, A., Riccio, E., Sabbatini, M., Andreucci, M., Del Rio, A. and Visciano, B. (2015) Effect of oral liposomal iron versus intravenous iron for treatment of iron deficiency anaemia in CKD patients: a randomized trial. Nephrol. Dial. Transplant. 30, 645-652.

Qian, H. R. and Yang, Y. (2016) Functional role of autophagy in gastric cancer. Oncotarget 7, 17641-17651.

Quach, C., Song, Y., Guo, H., Li, S., Maazi, H., Fung, M., Sands, N., O'Connell, D., Restrepo-Vassalli, S., Chai, B., Nemecio, D., Punj, V., Akbari, O., Idos, G. E., Mumenthaler, S. M., Wu, N., Martin, S. E., Hagiya, A., Hicks, J., Cui, H. and Liang, C. (2019) A truncating mutation in the autophagy gene UVRAG drives inflammation and tumorigenesis in mice. Nat. Commun. 10, 5681.

Raju, D., Hussey, S., Ang, M., Terebiznik, M. R., Sibony, M., GalindoMata, E., Gupta, V., Blanke, S. R., Delgado, A., Romero-Gallo, J., Ramjeet, M. S., Mascarenhas, H., Peek, R. M., Correa, P., Streutker, C., Hold, G., Kunstmann, E., Yoshimori, T., Silverberg, M. S., Girardin, S. E., Philpott, D. J., El Omar, E. and Jones, N. L. (2012) Vacuolating cytotoxin and variants in Atg16L1 that disrupt autophagy promote Helicobacter pylori infection in humans. Gastroenterology 142, 1160-1171.

Retnakumar, S. V. and Muller, S. (2019) Pharmacological autophagy regulators as therapeutic agents for inflammatory bowel diseases. Trends Mol. Med. 25, 516-537.

Rioux, J. D., Xavier, R. J., Taylor, K. D., Silverberg, M. S., Goyette, P., Huett, A., Green, T., Kuballa, P., Barmada, M. M., Datta, L. W., Shugart, Y. Y., Griffiths, A. M., Targan, S. R., Ippoliti, A. F., Bernard, E. J., Mei, L., Nicolae, D. L., Regueiro, M., Schumm, L. P., Steinhart, A. H., Rotter, J. I., Duerr, R. H., Cho, J. H., Daly, M. J. and Brant, S. R. (2007) Genome-wide association study identifies new susceptibility loci for Crohn disease and implicates autophagy in disease pathogenesis. Nat. Genet. 39, 596-604.

Rugge, M., Correa, P., Dixon, M. F., Fiocca, R., Hattori, T., Lechago, J., Leandro, G., Price, A. B., Sipponen, P., Solcia, E., Watanabe, H. and Genta, R. M. (2002) Gastric mucosal atrophy: interobserver consistency using new criteria for classification and grading. Aliment. Pharmacol. Ther. 16, 1249-1259.

Saber, S., Abd El-Kader, E. M., Sharaf, H., El-Shamy, R., El-Saeed, B., Mostafa, A., Ezzat, D. and Shata, A. (2020) Celastrol augments sensitivity of NLRP3 to CP-456773 by modulating HSP-90 and inducing autophagy in dextran sodium sulphate-induced colitis in rats. Toxicol. Appl. Pharmacol. 400, 115075.

Sanders, K. M., Koh, S. D., Ro, S. and Ward, S. M. (2012) Regulation of gastrointestinal motility--insights from smooth muscle biology. Nat. Rev. Gastroenterol. Hepatol. 9, 633-645.

Simon, P. M., Goode, P. L., Mobasseri, A. and Zopf, D. (1997) Inhibition of Helicobacter pylori binding to gastrointestinal epithelial cells by sialic acid-containing oligosaccharides. Infect. Immun. 65, 750757.

Somlyo, A. P. and Somlyo, A. V. (2003) Ca2+ sensitivity of smooth muscle and nonmuscle myosin II: modulated by $\mathrm{G}$ proteins, kinases, and myosin phosphatase. Physiol. Rev. 83, 1325-1358.

Stolte, M., Meier, E. and Meining, A. (1998) Cure of autoimmune gastritis by Helicobacter pylori eradication in a 21 -year-old male. $Z$. Gastroenterol. 36, 641-643.
Su, H., Hu, N., Yang, H. H., Wang, C., Takikita, M., Wang, Q. H., Giffen, C., Clifford, R., Hewitt, S. M., Shou, J. Z., Goldstein, A. M., Lee, M. P. and Taylor, P. R. (2011) Global gene expression profiling and validation in esophageal squamous cell carcinoma and its association with clinical phenotypes. Clin. Cancer Res. 17, 2955-2966.

Sugano, K., Tack, J., Kuipers, E. J., Graham, D. Y., El-Omar, E. M., Miura, S., Haruma, K., Asaka, M., Uemura, N. and Malfertheiner, P.; faculty members of Kyoto Global Consensus Conference (2015) Kyoto global consensus report on Helicobacter pylori gastritis. Gut 64, 1353-1367.

Sui, X., Liang, X., Chen, L., Guo, C., Han, W., Pan, H. and Li, X. (2017) Bacterial xenophagy and its possible role in cancer: a potential antimicrobial strategy for cancer prevention and treatment. Autophagy 13, 237-247.

Sun, D., Tao, W., Zhang, F., Shen, W., Tan, J., Li, L., Meng, Q., Chen, Y., Yang, Y. and Cheng, H. (2020) Trifolirhizin induces autophagy-dependent apoptosis in colon cancer via AMPK/mTOR signaling. Signal Transduct. Target. Ther. 5, 174.

Tanaka, S., Nagashima, H., Uotani, T., Graham, D. Y. and Yamaoka, Y. (2017) Autophagy-related genes in Helicobacter pylori infection. Helicobacter 22, e12376.

Tang, B., Li, N., Gu, J., Zhuang, Y., Li, Q., Wang, H. G., Fang, Y., Yu, B., Zhang, J. Y., Xie, Q. H., Chen, L., Jiang, X. J., Xiao, B., Zou, Q. M. and Mao, X. H. (2012) Compromised autophagy by MIR30B benefits the intracellular survival of Helicobacter pylori. Autophagy 8, 1045-1057.

Tang, L., Zeng, Y., Li, L., Wang, J., Peng, D., Zhang, T., Zhang, H. and An, X. (2020) Electroacupuncture upregulated ghrelin in rats with functional dyspepsia via AMPK/TSC2/Rheb-mediated mTOR inhibition. Dig. Dis. Sci. 65, 1689-1699.

Terebiznik, M. R., Raju, D., Vazquez, C. L., Torbricki, K., Kulkarni, R., Blanke, S. R., Yoshimori, T., Colombo, M. I. and Jones, N. L. (2009) Effect of Helicobacter pylori's vacuolating cytotoxin on the autophagy pathway in gastric epithelial cells. Autophagy 5, 370-379.

Tian, S., Guo, X., Yu, C., Sun, C. and Jiang, J. (2017) miR-138-5p suppresses autophagy in pancreatic cancer by targeting SIRT1. Oncotarget 8, 11071-11082.

Troilo, A., Grassi, A., Petrone, L., Cianchi, F., Benagiano, M., Bella, C. D., Capitani, N., Bitetti, J., D’Elios, S., Tapinassi, S., Azzurri, A., Alnwaisri, H., Romagnoli, J., Bizzaro, N., Bergman, M., Baldari, C. T. and D'Elios, M. M. (2019) Intrinsic factor recognition promotes T helper 17/T helper 1 autoimmune gastric inflammation in patients with pernicious anemia. Oncotarget 10, 2921-2929.

Tu, S. P., Quante, M., Bhagat, G., Takaishi, S., Cui, G., Yang, X. D., Muthuplani, S., Shibata, W., Fox, J. G., Pritchard, D. M. and Wang, T. C. (2011) IFN-gamma inhibits gastric carcinogenesis by inducing epithelial cell autophagy and T-cell apoptosis. Cancer Res. 71, 4247-4259.

Wang, C., Jiang, J., Ji, J., Cai, Q., Chen, X., Yu, Y., Zhu, Z. and Zhang, J. (2017) PKM2 promotes cell migration and inhibits autophagy by mediating PI3K/AKT activation and contributes to the malignant development of gastric cancer. Sci. Rep. 7, 2886.

Wang, C. W. and Klionsky, D. J. (2003) The molecular mechanism of autophagy. Mol. Med. 9, 65-76.

Wang, J., Miao, Y., Ran, J., Yang, Y., Guan, Q. and Mi, D. (2020a) Construction prognosis model based on autophagy-related gene signatures in hepatocellular carcinoma. Biomark. Med. 14, 1229-1242.

Wang, S. L., Shao, B. Z., Zhao, S. B., Fang, J., Gu, L., Miao, C. Y., Li, Z. S. and Bai, Y. (2018a) Impact of paneth cell autophagy on inflammatory bowel disease. Front. Immunol. 9, 693.

Wang, T., Liu, K., Wen, L., Yang, Y., Yin, X., Liu, K., Chen, Y., He, Y., Yang, M., Wei, Y., Wang, B. and Chen, D. (2020b) Autophagy and gastrointestinal diseases. Adv. Exp. Med. Biol. 1207, 529-556.

Wang, Y., Xu, W., Yan, Z., Zhao, W., Mi, J., Li, J. and Yan, H. (2018b) Metformin induces autophagy and G0/G1 phase cell cycle arrest in myeloma by targeting the AMPK/mTORC1 and mTORC2 pathways. J. Exp. Clin. Cancer Res. 37, 63.

Wang, Y. H., Wu, J. J. and Lei, H. Y. (2009) The autophagic induction in Helicobacter pylori-infected macrophage. Exp. Biol. Med. (Maywood) 234, 171-180.

Wang, Z., Shi, L., Hua, S., Qi, C. and Fang, M. (2019) IL-33 ameliorates experimental colitis involving regulation of autophagy of mac- 
rophages in mice. Cell Biosci. 9, 10.

Wehkamp, J. and Stange, E. F. (2020) An update review on the paneth cell as key to ileal Crohn's disease. Front. Immunol. 11, 646.

Wolpin, B. M., Rubinson, D. A., Wang, X., Chan, J. A., Cleary, J. M., Enzinger, P. C., Fuchs, C. S., McCleary, N. J., Meyerhardt, J. A., Ng, K., Schrag, D., Sikora, A. L., Spicer, B. A., Killion, L., Mamon, H. and Kimmelman, A. C. (2014) Phase II and pharmacodynamic study of autophagy inhibition using hydroxychloroquine in patients with metastatic pancreatic adenocarcinoma. Oncologist 19, 637 638.

Wu, J., Hu, L., Chen, M., Cao, W., Chen, H. and He, T. (2016) Pyruvate kinase M2 overexpression and poor prognosis in solid tumors of digestive system: evidence from 16 cohort studies. OncoTargets Ther. 9, 4277-4288.

Xavier, R. J. and Podolsky, D. K. (2007) Unravelling the pathogenesis of inflammatory bowel disease. Nature 448, 427-434.

Xia, M., Chen, H. and Liu, S. (2020) The synergy of resveratrol and alcohol against Helicobacter pylori and underlying anti-Helicobacter pylori mechanism of resveratrol. J. Appl. Microbiol. 128, 1179-1190.

Xiang, Z., Censini, S., Bayeli, P. F., Telford, J. L., Figura, N., Rappuoli, R. and Covacci, A. (1995) Analysis of expression of CagA and VacA virulence factors in 43 strains of Helicobacter pylori reveals that clinical isolates can be divided into two major types and that CagA is not necessary for expression of the vacuolating cytotoxin. Infect. Immun. 63, 94-98.

Xiao, B., Liu, Z., Li, B. S., Tang, B., Li, W., Guo, G., Shi, Y., Wang, F., Wu, Y., Tong, W. D., Guo, H., Mao, X. H. and Zou, Q. M. (2009) Induction of microRNA-155 during Helicobacter pylori infection and its negative regulatory role in the inflammatory response. J. Infect. Dis. 200, 916-925.

Xiao, M., Lin, C., Yang, Z., Tian, S., Huang, Y. and Fu, J. (2021) Compound TDB (Tricyclic decyl benzoxazole) induces autophagydependent apoptosis in the gastric cancer cell line MGC-803 by regulating PI3K/AKT/mTOR. Am. J. Transl. Res. 13, 73-87.

Xie, J., Li, L., Deng, S., Chen, J., Gu, Q., Su, H., Wen, L., Wang, S. Lin, C., Qi, C., Zhang, Q., Li, J., He, X., Li, W., Wang, L. and Zheng, L. (2020) Slit2/Robo1 mitigates DSS-induced ulcerative colitis by activating autophagy in intestinal stem cell. Int. J. Biol. Sci. 16 1876-1887.

Xu, J. L., Yuan, L., Tang, Y. C., Xu, Z. Y., Xu, H. D., Cheng, X. D. and Qin, J. J. (2020a) The role of autophagy in gastric cancer chemoresistance: friend or foe? Front. Cell Dev. Biol. 8, 621428.

Xu, J., Dai, S., Yuan, Y., Xiao, Q. and Ding, K. (2020b) A prognostic model for colon cancer patients based on eight signature autophagy genes. Front. Cell Dev. Biol. 8, 602174.

Xu, R., Ji, Z., Xu, C. and Zhu, J. (2018) The clinical value of using chloroquine or hydroxychloroquine as autophagy inhibitors in the treatment of cancers: a systematic review and meta-analysis. Medicine (Baltimore) 97, e12912.

Yan, S., Zhou, N., Zhang, D., Zhang, K., Zheng, W., Bao, Y. and Yang,
W. (2019) PFKFB3 inhibition attenuates oxaliplatin-induced autophagy and enhances its cytotoxicity in colon cancer cells. Int. J. Mol. Sci. 20, 5415

Yang, J. C., Yang, H. C., Shun, C. T., Wang, T. H., Chien, C. T. and Kao, J. Y. (2013) Catechins and sialic acid attenuate Helicobacter pylori-triggered epithelial caspase-1 activity and eradicate Helicobacter pylori infection. Evid. Based Complement. Alternat. Med. 2013, 248585.

Yang, J. S., Wang, C. M., Su, C. H., Ho, H. C., Chang, C. H., Chou, C. H. and Hsu, Y. M. (2018) Eudesmin attenuates Helicobacter pyloriinduced epithelial autophagy and apoptosis and leads to eradication of $\mathrm{H}$. pylori infection. Exp. Ther. Med. 15, 2388-2396.

Yue, P., Zhu, C., Gao, Y., Li, Y., Wang, Q., Zhang, K., Gao, S., Shi, Y., Wu, Y., Wang, B., Xie, J. and Meng, X. (2020) Development of an autophagy-related signature in pancreatic adenocarcinoma. Biomed. Pharmacother. 126, 110080.

Yue, W., Liu, Y., Li, X., Lv, L., Huang, J. and Liu, J. (2019) Curcumin ameliorates dextran sulfate sodium-induced colitis in mice via regulation of autophagy and intestinal immunity. Turk. J. Gastroenterol. 30, 290-298.

Zeh, H. J., Bahary, N., Boone, B. A., Singhi, A. D., Miller-Ocuin, J. L., Normolle, D. P., Zureikat, A. H., Hogg, M. E., Bartlett, D. L., Lee, K. K., Tsung, A., Marsh, J. W., Murthy, P., Tang, D., Seiser, N., Amaravadi, R. K., Espina, V., Liotta, L. and Lotze, M. T. (2020) A randomized phase II preoperative study of autophagy inhibition with high-dose hydroxychloroquine and gemcitabine/nab-paclitaxel in pancreatic cancer patients. Clin. Cancer Res. 26, 3126-3134.

Zhang, Q., Wang, X., Cao, S., Sun, Y., He, X., Jiang, B., Yu, Y., Duan, J., Qiu, F. and Kang, N. (2020) Berberine represses human gastric cancer cell growth in vitro and in vivo by inducing cytostatic autophagy via inhibition of MAPK/mTOR/p70S6K and Akt signaling pathways. Biomed. Pharmacother. 128, 110245.

Zhang, X., Jiang, A., Qi, B., Ma, Z., Xiong, Y., Dou, J. and Wang, J. (2015) Resveratrol protects against Helicobacter pylori-associated gastritis by combating oxidative stress. Int. J. Mol. Sci. 16, $27757-$ 27769.

Zhang, X., Li, Z., Xuan, Z., Xu, P., Wang, W., Chen, Z., Wang, S., Sun, G., Xu, J. and Xu, Z. (2018) Novel role of miR-133a-3p in repressing gastric cancer growth and metastasis via blocking autophagymediated glutaminolysis. J. Exp. Clin. Cancer Res. 37, 320.

Zhao, J. M., Liu, Y. N., Zheng, H. D., Huang, Y., Qi, Q., Liu, H. R., Shi, Y., Ma, X. P., Lu, Y. and Wu, L. Y. (2019) Effect of herb-partitioned moxibustion on autophagy and immune-associated gene expression profiles in a rat model of Crohn's disease. Evid. Based Complement. Alternat. Med. 2019, 3405146.

Zhou, X., Qian, H., Zhang, D. and Zeng, L. (2020) Inhibition of autophagy of Cajal mesenchymal cells by gavage of tong bian decoction based on the rat model of chronic transit constipation. Saudi J. Biol. Sci. 27, 623-628. 